\title{
Inter-generational ties, financial transfers and home-ownership support
}

\author{
Clara H. Mulder • Annika Smits
}

Received: 10 May 2011/Accepted: 1 June 2012/Published online: 19 June 2012

(C) The Author(s) 2012. This article is published with open access at Springerlink.com

\begin{abstract}
Home-ownership is transmitted between generations. Parental gifts form one of the mechanisms through which the intergenerational transmission of home-ownership takes place. Using the Netherlands Kinship Panel Study, we investigated the influence of parental and children's resources and other characteristics on financial support from parents to children. A major independent variable was parental home-ownership. As dependent variables, we distinguished between financial support towards buying a home, and financial support in the form of gifts of $€ 5,000$ or more ever received. By making this distinction, we could test whether homeowner parents were particularly likely to help their children become homeowners rather than giving other types of financial help. The results did not indicate such specific gift-giving: parental home-ownership was just as important to other types of monetary support as to home-ownership support. However, the distance to the place where the adult child had grown up was negatively associated with receiving home-ownership support but not with receiving other financial transfers.
\end{abstract}

Keywords Home-ownership · Financial transfers · Family relations

\section{Introduction}

A well-established finding in the literature is that home-ownership is intergenerationally transmitted: children of homeowners are more likely to become homeowners themselves (Henretta 1984, 1987; Mulder and Wagner 1998; Mulder and Smits 1999; Helderman and Mulder 2007). There is even some evidence that the association between parents' and their

\footnotetext{
C. H. Mulder $(\bowtie)$

Population Research Centre, University of Groningen, P.O.Box 800, 9700 AV Groningen, The Netherlands

e-mail: c.h.mulder@rug.nl
}

\author{
A. Smits \\ Department of Health Promotion and Epidemiology, Regional Public Health Service (GGD) Nijmegen, \\ P.O.Box 1120, 6501 BC Nijmegen, The Netherlands \\ e-mail: asmits1@ggd-nijmegen.nl
}


adult children's home-ownership has increased, at least in the Netherlands (Smits and Mulder 2008).

An important mechanism underlying the association between parents' and their children's home-ownership is formed by financial transfers-gifts, loans and mortgage guarantees-from parents to children. Parents who own their home are considerably more likely to provide financial support to their children than parents who rent (Mulder and Smits 1999, for the Netherlands; Grundy 2005, for Great Britain). Those who ever received a gift from their parents are more likely to be homeowners (Helderman and Mulder 2007, for the Netherlands), and gifts allow households to buy homes earlier and to buy more expensive homes (Engelhardt and Mayer 1994, 1998, for the United States; Guiso and Jappelli 2002, for Italy). As Mayer and Engelhardt (1996) argue, the decline of home-ownership among young households in the United States in the 1980s and early 1990s was accompanied by an increasing dependence on gifts from relatives for acquiring home-ownership among young prospective homeowners. In Norway, a greater proportion of younger than older people have ever received home loans or other financial support for housing from their parents (Gulbrandsen and Langsether 2003).

Financial transfers from parents to children, and particularly those related to homeownership, are obviously an important research topic. But the results from previous research on this topic are not easy to interpret, owing to a great variation in what kinds of transfers are measured. Some studies focus on transfers directed to housing (for example Gulbrandsen and Langsether 2003) or, more specifically, on help with the down payment for a house (Engelhardt and Mayer 1994). Many other studies focus on financial transfers in general. Examples of transfers that have been investigated are the receipt of a loan or gift of at least 200 US dollars in the past 5 years (Eggebeen and Hogan 1990) or 2 years (Amato et al. 1995); Cox and Rank (1992) employ the positive difference between amounts received and amounts given to parents. This variation in specifications of the dependent variable is probably a major cause of mixed findings about, for example, the impact of the adult child's income on the likelihood of receiving financial transfers. In fact in one exceptional study that employed two different dependent variables, after accounting for the parents' income, a negative effect was found of the child's income on the likelihood of receiving a transfer, but a positive effect on the amount received (Cox and Rank 1992).

Thus far, scholars who investigated the intergenerational transmission of home-ownership perceived parental housing gifts as part of a resource effect: home-owners often have more assets and savings available than renters (Helderman and Mulder 2007) and are therefore in a more favorable position for gift-giving. From this point of view, homeowner parents are more likely than renter parents to provide any kind of financial assistance, either or not directly aimed at supporting homeownership. There should thus be no difference between the impacts of parental home-ownership on either type of gifts.

In this paper, we propose an alternative hypothesis for the positive impact of parental gifts on homeownership: the ownership-promotion hypothesis. If homeowner parents wish their children to become homeowners, and children of homeowners have a particular preference for home-ownership, homeowner parents should be keen on using their resources to promote their children's home-ownership. If this were true, a positive impact of parental home-ownership on gifts towards home-ownership would partly be caused by this wish to promote home-ownership rather than just by a resource effect. Its impact on gifts towards home-ownership should therefore be greater than on other gifts.

Using data from the Netherlands Kinship Panel Study and logistic regression models, we aim to answer the following research question: To what extent do homeowner parents use their resources specifically for the purpose of stimulating their children's home- 
ownership? We focus on two types of transfers: financial assistance towards buying a home, and financial assistance in the form of gifts of $€ 5,000$ or more. We test whether the influence of parental home-ownership, the parents' and the children's other resources and other theoretically important independent variables differs between these types of transfers.

\section{Theoretical background}

In today's western societies, there is a net downward flow of private resources from the older generations to their adult children. In the United States, for example, $17 \%$ of the respondents had received a financial gift or loan from their parents in the 5 years before the 1987-1988 National Survey of Families and Households (excluding help with mortgage payments), and only $4 \%$ had given money to their parents (Eggebeen and Hogan 1990; see also Attias-Donfut et al. 2005 and Albertini et al. 2007, for 10 European countries). There are not many signs that state support has replaced family support: on the contrary, most evidence seems to suggest that state support and family support tend to go together (Kohli 1999; Attias-Donfut and Wolf 2000; Motel-Klingebiel et al. 2005), although Reil-Held (2006) concluded differently for Germany.

Research on parental gift-giving specifically towards home-ownership is scarce, but there is reason to believe that the role of parental housing assistance is becoming increasingly important for young adults' access to home-ownership. Today's parents have more assets and fewer children than yesterday's, and today's housing markets provide more possibilities for financial help from parents, at least in the Netherlands (Mulder 2007). Evidence from Norway suggests that the extent to which parents give financial support for housing has increased in the past few decades. The percentage having received a home loan or other financial support for housing purposes from parents or parents-in-law was greater among younger than among older people. Among those aged 20-29 in 2001, the percentage that had received such support was 20 compared with 11 among those aged 60-69 and 4 among those aged over 69 (Gulbrandsen and Langsether 2003).

According to Poggio (2008), the role of the family in supporting entry into homeownership is especially large in countries with a lack of affordable alternative housing (for example in the rental sector) and with a strong emphasis on family support as a social norm. These conditions are not met in the Netherlands. The Netherlands is characterized by a rather generous welfare system in the sense of both social support and housing support. It has a well-developed mortgage market in which banks are willing to provide loans up to a high percentage of the house value (Mulder and Billari 2010). Yet, parental housing assistance is also quite common in the Netherlands (Helderman and Mulder 2007).

As mentioned, we want to set a newly proposed ownership promotion hypothesis next to the resource effect hypothesis. Whereas the resource effect refers to the parents' ability to give support, gift-giving to promote home-ownership occurs because of their willingness to do so. Theoretical arguments about resources and willingness to provide support are broader than just the resource effect of parental home-ownership and gift-giving to promote home-ownership, and it is this broader picture that we draw here.

\subsection{Parental resources and financial support}

The parents' ability to provide support (either gift-giving for home-ownership, or other financial support) obviously depends on their resources. All the available empirical evidence points in the same direction: the likelihood that a parent supports a child financially 
is positively influenced by the parents' income, socioeconomic status, level of education (Cox and Rank 1992; Mulder and Smits 1999; Henretta et al. 2002) and, after accounting for these, also by wealth (Pezzin and Schone 1999; Gulbrandsen and Langsether 2003). The positive effect of parental home-ownership on the likelihood that the parents provide financial support (Mulder and Smits 1999; Grundy 2005) is likely to also be associated with resources: homeowner parents may withdraw equity from their home to support a child, and when their children have reached adult ages they frequently have paid off much of their mortgage and thus have low housing costs (Helderman and Mulder 2007). Moreover, it is likely that homeowner parents have additional savings reserved for the maintenance and improvement of their home, which might also be used to support their children financially. Following from the above, we expect to find that homeowner parents are more likely than renter parents to give financial support, regardless of support type. We refer to this as the resource effect: the positive effect of parental home-ownership on giftgiving does not differ by support type.

Next to the resource effect hypothesis that is related to parental home-ownership, several other factors can be identified that are related to resources and thus, through resources, to the likelihood of parental support. If parents have more than one child, the children might have to compete for the available resources or they have to be shared between the children. One would therefore expect the likelihood of parent-child transfers to be smaller if the child has more siblings. This expectation is also supported by univocal evidence. Norwegian parents were less likely to give financial housing support to a child if they had more other children (Gulbrandsen and Langsether 2003). Likewise, adult children who had more siblings were less likely to receive financial support from their parents (Eggebeen and Hogan 1990; Cox and Rank 1992; McGarry and Schoeni 1997), even though in Great Britain the likelihood of a parent giving financial support to any adult child was found to be greater if the parent had more children (Grundy 2005).

More parental resources are probably usually also available if both parents are alive than if one parent is no longer alive. In the United States, a greater 'number of living parents' was indeed associated with a greater likelihood of financial parent-child transfers (Eggebeen and Hogan 1990; Cox and Rank 1992). Furthermore, with older ages at childbirth, the parents have had more time to accumulate resources. The age difference between the respondent and his or her mother is therefore expected to be positively associated with the likelihood of having received financial support. This also holds for the respondents' (and their parents') age in years. The older someone is, the more resources he or she will have accumulated. But age also just stands for the passage of time: the more time that has passed, the greater the likelihood that a gift has been given. This time-passage effect could partly be offset by the fact that age also indicates birth cohort: in the period we study (which did not include the recent financial and housing-market crisis), younger cohorts were generally wealthier and operated in a housing market in which home-ownership became increasingly common.

Parental divorce might also lead to fewer parental resources, but the arguments about the effect of parental divorce on support towards children are usually derived from the perspective of relationship quality (see below).

\subsection{The parents' willingness to provide financial support}

Why would parents want to give money to their adult children? Mayer and Engelhardt (1996) provide a short and simple answer by putting forward three possible reasons for providing help with the down payment for a house: "Transfers might be targeted to 'constrained' households; they might be made to households showing 'merit' through 
education, marriage, or children; or they might just be the conduit for the inter-generational transmission of wealth" (p. 64). With some adaptations to Mayer and Engelhardt's reasons, we propose four purposes of financial parent-child transfers. From each of these, hypotheses can be derived concerning the influence of various factors on the likelihood of a transfer; the fourth leads to our ownership-promotion hypothesis.

\subsection{Parents' willingness: response to need}

In line with Mayer and Engelhardt's (1996) first possible reason for giving help, parents may provide financial support to an adult child in response to the child's needs. If financial support is mainly given in response to needs, one would expect the likelihood of a financial transfer to be greater if the child's own financial resources are insufficient; this should hold true after accounting for parental resources. Part of the evidence indeed points into the direction that a higher income of the child is inversely related to the likelihood of financial parenthood-child transfers (Furstenberg et al. 1995; McGarry and Schoeni 1997; Berry 2008). Adult children who have insufficient income or who just manage on their income are more likely to receive home loans or other financial support for housing from their parents (Gulbrandsen and Langsether 2003) and those with lower incomes (Mayer and Engelhardt 1996) and with credit problems (Engelhardt and Mayer 1994) receive more help with the down payment for a home. Other evidence, however, contradicts these findings. Eggebeen and Hogan (1990) found that poor children were less likely to receive money from parents than those with higher incomes - it should be noted, though, that they only accounted for parental education, not for parental income. Cox and Rank (1992) found that adult children with higher incomes were less likely to receive a transfer, but the amount was greater. This mixed evidence may reflect that financial support is not just given in response to the child's needs, but also serves other purposes. Furthermore, reverse causality may also be an issue here: some adult children may have achieved their better position partly through parental support.

From a response perspective, an alternative hypothesis may be proposed specifically for gifts to support home-ownership. For adult children with the least resources, home-ownership may be out of reach even with support from the parents. It might not even be desirable, especially in the context of the Netherlands. In the Netherlands, those with lower incomes are eligible for individual rent subsidies, and social housing not only comprises a considerable share of the housing stock but is of good quality.

\subsection{Parents' willingness: reward for merit}

In line with Mayer and Engelhardt's (1996) 'merit' as a possible reason for giving help, parents may provide financial support to an adult child to reward the child for behavior according to their wishes or to social norms. Mayer and Engelhardt mention education, marriage, and having children as merits that might be rewarded by parents. If financial transfers are mainly rewards, one would expect a high level of education (after accounting for the parents' level of education), being married, and having children to be associated with a greater likelihood of receiving financial support from a parent. Conversely, divorce of an adult child might lead to less support. For a positive association with level of education, some empirical evidence can be found in Eggebeen and Hogan's (1990) study, but Gulbrandsen and Langsether (2003) found no effect on housing support. For being married, either no effect (Gulbrandsen and Langsether 2003) or the opposite has been found from what would be expected from a reward perspective: married persons were less likely than the unmarried to receive financial support from their parents (Eggebeen and 
Hogan 1990; Furstenberg et al. 1995; McGarry and Schoeni 1997). This finding could actually be interpreted from the response perspective: Divorced and single adult children cannot pool resources with a partner and may therefore have a greater need for financial support. For having children, the evidence is scarce and mixed: Furstenberg et al. (1995) report a negative effect, whereas McGarry and Schoeni (1997) find a positive effect. Just like divorce, having children may not only be connected with merit but also with a greater need for support. But in the case of having children, one would expect a positive association with receiving support from either perspective.

\subsection{Parents' willingness: reinforcement of a good relationship}

Another purpose of giving financial support may be to reinforce a good relationship with the child, either for altruistic or for exchange motives, for example exchange for company and care. Some have tried to confront theories in which parent-child transfers are explained from altruistic motives with theories in which they are explained from exchange or other motives (Cox 1987; Cox and Rank 1992; Altonji et al. 1997). It has also been argued, however, that altruistic and exchange motives are not so easily distinguished from each other and that it may be artificial to draw this distinction (Grundy 2005). Indeed, both theories lead to the prediction that parents who have a good relationship with an adult child are more likely to give financial support.

Because of causality issues particularly but not exclusively associated with the use of cross-sectional data - the good relationship might just as well have followed from the financial support as the other way around-many studies use indirect indicators of good relationships that are unlikely to have been influenced by financial support. One possibility would be to use a measurement of relationship quality from a more distant past, for example during childhood, but childhood memories may well be colored by later experiences. Various studies have focused on the influence of parental divorce on parent-child transfers. Parental divorce seems to be a good indicator of less strong bonds between parents and children; it reduces the quality of the relationship between them (Pezzin and Schone 1999; De Jong Gierveld and Dykstra 2002). Remarriage further weakens the bond between the generations (Cooney and Uhlenberg 1990). In the United States, divorced mothers and fathers were indeed less likely to give financial support to their children (Amato et al. 1995; see also Grundy 2005, for Great Britain), but the evidence suggests that the association between parental divorce and financial transfers is complex. First of all, it seems to depend on the timing of the parental divorce. Parental divorce taking place in someone's childhood years seems to lead to a decrease in transfers, particularly from fathers, but later parental divorce does not seem to affect transfers (Furstenberg et al. 1995). Because after a parental divorce the support potentially comes from two parental households, adult children of divorced parents seem to end up being just as likely to receive financial support from a parent as those whose parents have not divorced (Amato et al. 1995).

Women tend to have stronger relationships with family members than men (Rossi and Rossi 1990). They might therefore be expected to receive more financial support. It is, however, also possible that some parents still think about financial needs and responsibilities in a gendered way-sons should provide for their families whereas daughters can rely on their husbands - or that some adult children think similarly, so that sons may be more inclined than daughters to ask their parents for financial help. Men are also known to be more likely to own a home than women (Blaauboer 2010) and may rely on parental support for home-ownership more frequently than women. The empirical evidence does not point to gender differences (Eggebeen and Hogan 1990; McGarry and Schoeni 1997; 
Gulbrandsen and Langsether 2003). This might mean the potential positive and negative effects counterbalance each other or none is present.

Geographical distance is associated with less parent-child contact (Greenwell and Bengtson 1997; Bonvalet and Maison 2007) and seems to decrease the likelihood of various types of support between generations (Rossi and Rossi 1990; Mulder and Van der Meer 2009). This is true even in the Netherlands, a small country where distances between parents and children are short. Distance thus affects the frequency of interaction in parentchild relationships, even though it does not necessarily affect their quality (Bonvalet and Maison 2007, found that the likelihood of parents considering their children as emotionally close was not affected by distance). One would therefore expect children who live close to their parents to receive more support. As shown by Litwak and Kulis (1987), financial gifts are indeed affected by distance, although less so than practical support. According to McGarry and Schoeni (1997), children in the United States who live less than 10 miles from their parents are more likely to receive financial transfers from them than those who live farther away. It should be noted that the causal direction between distance and financial support is not straightforward. Tomassini et al. (2003), for example, seem to be convinced that housing assistance leads to proximity rather than the other way around.

\subsection{Parents' willingness: ownership promotion}

A fourth purpose of giving financial support may be to encourage behavior of the child that conforms to their wishes. This purpose is similar to the reward purpose but the difference is that encouragement precedes the desired behavior of the child. As has been argued in the literature, parents who own their home are likely to want their children to be homeowners too. At the same time, children of homeowners are more likely than children of renters to wish to become homeowners themselves. Along these two lines, it has been hypothesized, homeowner parents tend to socialize their children towards home-ownership (Henretta 1984; Mulder and Smits 1999; Helderman and Mulder 2007; Smits and Mulder 2008). If this is true, the encouragement argument leads to the hypothesis that homeowner parents are particularly likely to provide support for home-ownership compared with other financial support: the ownership-promotion hypothesis.

\section{Data and methods}

\subsection{Sample}

We used the main sample from the first wave of the Netherlands Kinship Panel Study, complemented with additional information from the second wave (Dykstra et al. 2005, 2007, $\mathrm{N}=8,161$ main respondents aged $18-79$ in the first wave). These data contain extensive information on family relations, including the receipt of financial gifts from the parents of $€ 5,000$ or over and financial assistance in becoming a homeowner. The selection of respondents comprised those who did not live with their parents $(n=7,884)$. Cases with missing values on the dependent or some of the independent variables ( $\mathrm{n}=106$, which amounts to $1.3 \%$ ) were also excluded, leading to an analytical sample of 7,778 dyads between respondents and their parents. Note that there was no requirement that one or both parents had to be alive at the moment of interview. For the information about parental resources to be available, however, at least one parent had to be alive at age 15 of the respondent. 
A disadvantage of the data is that no information is available about the timing of the gifts. This is not very problematic for assessing the influence of parental resources, because these were measured for age 15 of the respondent while transfers of large amounts, and particularly housing assistance, will usually only take place after that age. But for associations between financial support and the adult child's characteristics, the time ordering of receiving financial assistance and, for example, the attainment of the highest level of education is uncertain. The direction of causality between receiving assistance and the independent variables for the adult child is therefore questionable. Using only those receiving financial assistance between the first and second NKPS waves did not solve this problem, for two reasons. First, too few respondents reported receiving assistance between waves. Secondly, among those who did, a disproportionately high share had also reported receiving assistance in the first wave. Apparently, quite a few parents repeatedly help their children financially and/or quite a few respondents report the same financial transfer twice.

\subsection{Variables}

\subsubsection{Dependent variables}

The first dependent variable is whether the respondent ever received a gift of at least $€$ 5,000 , either in the form of one amount or in the form of regular transfers. The second dependent variable is whether the respondent ever received financial help from a parent to purchase a home. Both variables were coded 1 if the respondent reported having received a gift before the first NKPS wave, between the first and second waves, or both. For those respondents who did not participate in Wave 2 or for whom information about parental support was missing in Wave 2, only information from Wave 1 was used.

\subsubsection{Parental resources}

The father's socio-economic status was measured as the International Social-Economic Index (ISEI; Ganzeboom et al. 1992) of the job he held when the respondent was around 15 years old. A dummy indicates whether the father's ISEI was unknown (1.5\% of the cases); those with a value 1 on that dummy were assigned the mean (this procedure is known as 'missing substitution'). Because generations are observed in which mothers were unlikely to be employed, no separate variable was included for the mother's socio-economic status. Instead, a dummy indicates whether the mother usually worked for pay in the period until the respondent turned 15. Level of education of the father and mother was measured in four categories: up to primary school; up to middle vocational education; higher vocational or university; education unknown. Parental home-ownership was measured as whether the respondent's parents owned their home when the respondent was around 15 years old. The number of siblings was measured as the number of biological siblings that survived until age 18 of the respondent. Numbers over 9 were recoded to 9 . Indicators were also included of whether the father and mother had died before or after the respondent had turned 18 . The age difference with the mother was measured in years.

\subsubsection{Parents' willingness: need}

The need for assistance was indicated by socio-economic status, which was measured as the ISEI of the respondent's job at the time of the interview. When the respondent did not 
have a job at that time, the ISEI of the last job before the interview was used, or when that information was not available, the ISEI of the first job. Although NKPS also contains information about income, a measure of socio-economic status was preferred because socio-economic status is much less volatile than income. It should be borne in mind that the causality might run from parental support to the respondent's socio-economic status rather than the other way around. This problem might be alleviated by using the socioeconomic status of the first job rather than that of the current or last job. Note, however, that information about the first job was only available for $16 \%$ of the respondents, so we could not choose to use the first job only. Additional analyses using these $16 \%$ revealed no statistically significant effect of the ISEI of the first job on the likelihood of receiving financial assistance.

\subsubsection{Parents' willingness: merit}

The respondent's level of education was measured in four categories: up to lower secondary or lower vocational; up to higher secondary or middle vocational; higher vocational; university. This categorization is less detailed in the lower levels than the categorization used for the parents and more detailed in the upper levels to reflect cohort changes in the distribution of levels of education. To measure whether the respondent had married, we distinguished between those who had never had a partner, those who had had at least one partner but had not married, and those who had ever married. A dummy variable was used to indicate whether the respondent had had at least one child, and another dummy indicates whether the respondent had ever divorced.

\subsubsection{Parents' willingness: relationship quality}

As mentioned, the respondents' memory of the quality of the relationship with the parents might be colored by later evaluations of this relationship. We therefore included a more factual measure of the family atmosphere in the respondent's youth, referring to the relationship between the parents (compare Blaauboer and Mulder 2010). This measure included five items on the occurrence of arguments between the parents and whether they had lived separately for a while around age 15 of the respondent. When one or both parents were no longer alive at the time the respondent was 15 years old or when the parents had divorced before that age, the items referred to the situation immediately preceding the death of a parent or the divorce. The internal consistency of the items was good; Cronbach's alpha was .78. We used the mean score on these items, after which three categories were constructed to indicate whether the parental relationship was of low, medium, or high quality. A fourth category was added for a small number of respondents whose parents had never lived together $(n=148)$.

Parental divorce was measured in three categories: no parental divorce (reference), divorce when the respondent was aged under 18, and divorce when the respondent was aged 18 or over. The closer family relationships of women were indicated with a dummy that had the value 1 for female respondents. The distance to the place where the respondent grew up was derived from the coordinates of the municipality in which the respondent lived at age 15 and those of the respondent's postal code at the time of the NKPS interview. If the place of residence at age 15 was unknown, the distance to the parent living closest was taken instead. If that distance was also missing, missing substitution was applied and a dummy for missing distance was assigned the value 1 . The distance was measured in 
Table 1 Descriptive statistics of categorical variables $(\mathrm{N}=7,778)$

\begin{tabular}{|c|c|}
\hline & $\%$ in sample \\
\hline Homeownership support & 9.0 \\
\hline Money support $\geq € 5,000$ & 15.5 \\
\hline Father's ISEI missing & 1.5 \\
\hline Mother worked & 19.0 \\
\hline Father's education (ref $=$ up to primary) & 32.6 \\
\hline Up to middle vocational & 42.7 \\
\hline Higher vocational/university & 16.5 \\
\hline Unknown & 8.3 \\
\hline Mother's education (ref $=$ up to primary) & 38.8 \\
\hline Up to middle vocational & 49.3 \\
\hline Higher vocational/university & 7.0 \\
\hline Unknown & 5.0 \\
\hline Parents homeowner at R's age 15 & 51.9 \\
\hline Father deceased $($ ref $=$ no $)$ & 43.3 \\
\hline Before R's age 18 & 5.6 \\
\hline R's age 18 or over & 51.1 \\
\hline Mother deceased $(\mathrm{ref}=\mathrm{no})$ & 59.6 \\
\hline Before R's age 18 & 2.8 \\
\hline R's age 18 or over & 37.6 \\
\hline ISEI missing & 3.6 \\
\hline Education (ref $=$ up to lower secondary) & 35.4 \\
\hline Upper secondary/middle voc. & 30.8 \\
\hline Higher vocational & 23.6 \\
\hline University & 10.2 \\
\hline Ever partner $($ ref $=$ no $)$ & 8.4 \\
\hline Unmarried only & 17.4 \\
\hline Married & 74.2 \\
\hline Children & 71.3 \\
\hline Ever divorced & 14.9 \\
\hline Parental relationship quality at R's age 15 (ref $=$ low) & 28.1 \\
\hline Medium & 38.1 \\
\hline High & 31.9 \\
\hline Parents never lived together & 1.9 \\
\hline Parents divorced $(\mathrm{ref}=\mathrm{no})$ & 88.9 \\
\hline Before R's age 18 & 7.9 \\
\hline R's age 18 or over & 3.2 \\
\hline Women & 58.7 \\
\hline Distance missing & 4.6 \\
\hline Foreign born & 6.0 \\
\hline
\end{tabular}

kilometers along a straight line. Distances between 0 and $1 \mathrm{~km}$ were recoded to 1 , after which the natural logarithm was taken. Descriptive statistics of the dependent and independent variables are in Tables 1 and 2 . 
Table 2 Descriptive statistics of continuous variables

\begin{tabular}{llrr}
\hline & N & Mean & \multicolumn{1}{c}{ SD } \\
\hline Age difference with mother & 7,778 & 29.13 & 5.94 \\
N siblings & 7,778 & 2.93 & 2.42 \\
Age & 7,778 & 47.23 & 14.69 \\
Father's ISEI & 7,662 & 4.64 & 1.58 \\
ISEI & 7,497 & 4.85 & 1.65 \\
Log distance & 7,419 & 31.43 & 43.51 \\
\hline
\end{tabular}

\subsection{Method}

Because it is likely that the receipt of monetary support and ownership are correlated (parents who are both willing and able to support their children financially might do so at multiple occasions and for multiple purposes), we first checked the correlation between both support types. The correlation was positive, but not too high: .31. We then ran crosstabs of receiving support by the parents' tenure status at age 15 to get a first indication of whether homeowner parents are more likely to give support in general (supporting the resource effect hypothesis) or are more inclined to give ownership support (favoring the ownership promotion hypothesis). Next, we estimated logistic regression models of whether a respondent received a gift and whether he or she received financial assistance to purchase a home. To compare the parameters for the two dependent variables, we used seemingly unrelated estimation (Clogg et al. 1995). This technique allows for the testing of the null hypothesis that the parameters are the same between models and uses fewer degrees of freedom than models that include interaction effects. A greater parameter for parental ownership in the model for support in becoming a homeowner than in the model for other monetary support would indicate support for the hypothesis about encouragement of home-ownership by homeowner parents.

\section{Results}

Table 3 shows the percentages of respondents who received support from a parent by tenure status of the parent. Of those with homeowner parents, about $22 \%$ received monetary support and $13 \%$ received ownership support. These percentages are lower for those with renter parents: 8.0 and $4.7 \%$, respectively.

\subsection{Parental resources}

The findings for parental resources were largely as expected: the more resources the parents had, the greater the likelihood they supported their children with money and the greater the likelihood they helped them purchase a home (see Table 4). This is true of the father's socio-economic status (the greater his ISEI, the greater the likelihood of parental

Table 3 Percentages having received support from a parent, by parental homeownership at respondent's age $15, \mathrm{~N}=7,778$

\begin{tabular}{lcc}
\hline Parents homeowner & Money support & Ownership support \\
\hline Yes & 22.40 & 12.99 \\
No & 8.04 & 4.65 \\
Total & 15.49 & 8.97
\end{tabular}


Table 4 Logistic regression of support received from a parent

\begin{tabular}{|c|c|c|c|c|c|}
\hline & \multicolumn{2}{|c|}{ Money support } & \multicolumn{2}{|c|}{ Ownership support } & \multirow{2}{*}{$\begin{array}{l}\text { Difference } \\
P>\chi^{2}\end{array}$} \\
\hline & $\mathrm{B}$ & $P>|z|$ & $\mathrm{B}$ & $P>|z|$ & \\
\hline Father's ISEI & 0.124 & 0.000 & 0.077 & 0.011 & 0.152 \\
\hline Father's ISEI missing & -0.374 & 0.353 & -1.760 & 0.086 & 0.212 \\
\hline Mother worked & 0.263 & 0.001 & 0.186 & 0.074 & 0.499 \\
\hline \multicolumn{6}{|c|}{ Father's education (ref $=$ up to primary) } \\
\hline Up to middle vocational & 0.157 & 0.094 & 0.179 & 0.125 & 0.864 \\
\hline Higher vocational/university & 0.117 & 0.353 & 0.436 & 0.004 & 0.060 \\
\hline Unknown & -0.105 & 0.528 & 0.234 & 0.256 & 0.151 \\
\hline \multicolumn{6}{|c|}{ Mother's education (ref $=$ up to primary) } \\
\hline Up to middle vocational & 0.017 & 0.848 & 0.014 & 0.896 & 0.982 \\
\hline Higher vocational/university & 0.050 & 0.726 & 0.082 & 0.640 & 0.874 \\
\hline Unknown & -0.080 & 0.683 & -0.512 & 0.071 & 0.155 \\
\hline Parents homeowner at R's age 15 & 1.050 & 0.000 & 1.095 & 0.000 & 0.679 \\
\hline $\mathrm{N}$ siblings & -0.165 & 0.000 & -0.213 & 0.000 & 0.070 \\
\hline \multicolumn{6}{|l|}{ Father deceased $(\mathrm{ref}=\mathrm{no})$} \\
\hline Before age 18 & -0.263 & 0.149 & -0.764 & 0.003 & 0.094 \\
\hline Age 18 or over & 0.032 & 0.746 & -0.032 & 0.783 & 0.631 \\
\hline \multicolumn{6}{|l|}{ Mother deceased $(\mathrm{ref}=\mathrm{no})$} \\
\hline Before age 18 & -0.535 & 0.034 & -0.582 & 0.072 & 0.881 \\
\hline Age 18 or over & -0.413 & 0.000 & -0.323 & 0.010 & 0.543 \\
\hline Age difference with mother & 0.043 & 0.000 & 0.044 & 0.000 & 0.898 \\
\hline ISEI & 0.035 & 0.185 & 0.003 & 0.934 & 0.377 \\
\hline ISEI missing & -0.507 & 0.023 & 0.140 & 0.553 & 0.020 \\
\hline \multicolumn{6}{|c|}{ Education (ref $=$ up to lower secondary) } \\
\hline Upper secondary/middle voc. & 0.212 & 0.031 & 0.224 & 0.083 & 0.932 \\
\hline Higher vocational & 0.285 & 0.012 & 0.572 & 0.000 & 0.070 \\
\hline University & 0.525 & 0.000 & 0.596 & 0.001 & 0.724 \\
\hline \multicolumn{6}{|l|}{ Ever partner $(\mathrm{ref}=\mathrm{no})$} \\
\hline Unmarried only & 0.208 & 0.145 & 0.344 & 0.072 & 0.522 \\
\hline Married & 0.341 & 0.027 & 0.399 & 0.048 & 0.798 \\
\hline Children & 0.003 & 0.978 & 0.060 & 0.623 & 0.648 \\
\hline Ever divorced & -0.010 & 0.924 & 0.080 & 0.516 & 0.505 \\
\hline \multicolumn{6}{|c|}{ Parental relationship quality at R's age $15(\mathrm{ref}=$ low $)$} \\
\hline Medium & -0.148 & 0.074 & -0.032 & 0.754 & 0.314 \\
\hline High & -0.024 & 0.784 & -0.143 & 0.207 & 0.340 \\
\hline Parents never lived together & -0.283 & 0.417 & 0.022 & 0.957 & 0.533 \\
\hline \multicolumn{6}{|l|}{ Parents divorced $(\mathrm{ref}=\mathrm{No})$} \\
\hline Before age 18 & -0.467 & 0.003 & -0.372 & 0.063 & 0.659 \\
\hline Age 18 or over & 0.011 & 0.955 & -0.403 & 0.122 & 0.173 \\
\hline Woman & -0.013 & 0.846 & -0.128 & 0.147 & 0.227 \\
\hline Log distance & 0.013 & 0.582 & -0.071 & 0.016 & 0.009 \\
\hline Distance missing & -0.176 & 0.445 & 0.299 & 0.287 & 0.110 \\
\hline Age & 0.006 & 0.114 & 0.027 & 0.000 & 0.000 \\
\hline
\end{tabular}


Table 4 continued

\begin{tabular}{|c|c|c|c|c|c|}
\hline & \multicolumn{2}{|c|}{ Money support } & \multicolumn{2}{|c|}{ Ownership support } & \multirow{2}{*}{$\begin{array}{l}\text { Difference } \\
P>\chi^{2}\end{array}$} \\
\hline & $\mathrm{B}$ & $P>|\mathrm{z}|$ & $\mathrm{B}$ & $P>|\mathrm{z}|$ & \\
\hline Foreign born & 0.049 & 0.809 & -0.158 & 0.547 & 0.468 \\
\hline Constant & -4.662 & 0.000 & -5.848 & 0.000 & \\
\hline Log likelihood & $-3,017.8$ & & $-2,122.2$ & & \\
\hline$\chi^{2}(\mathrm{df}=35)$ & 671.56 & & 452.43 & & \\
\hline Significance model & 0.000 & & 0.000 & & \\
\hline Pseudo R square & 0.10 & & 0.10 & & \\
\hline $\mathrm{N}$ & 7,778 & & 7,778 & & \\
\hline
\end{tabular}

support), whether the mother used to work for pay around age 15 of the respondent (when she did, the likelihood of parental support was enhanced), parental home-ownership (parents who owned their home when the respondent was 15 years old were considerably more likely to provide support), the number of other siblings that might qualify for support (the more siblings, the smaller the likelihood of parental support), whether the father or mother had died before the respondent turned 18 (the death of a parent is associated with a smaller likelihood of support) and the age difference with the mother (the greater this difference, the greater the likelihood of support). Net of the father's socio-economic status and the labor-force participation of the mother, the parents' levels of education do not seem to matter very much to the likelihood of support. An exception was a higher vocational or university education of the father: this significantly enhanced the likelihood of homeownership support. Remarkably, no negative effect was found for the death of the father after the respondent turned 18. Possibly, many widows use their husband's inheritance to support their children financially.

\subsection{Parents' willingness to provide support}

The results provide no indications of responsiveness of the parents to the adult child's need: the association between the adult child's socio-economic status and the likelihood of parental support is not significant and its sign is positive for support with money.

The findings are more in line with an interpretation of parental support as a reward for merit. Those with higher levels of education are more likely to have received money or home-ownership support. This is also true of those who ever had a partner, particularly if they were married to that partner. It should be noted, however, that reward for merit is not the only possible interpretation of these findings. The highly educated may have needed the financial support to achieve their high education, and they may have been more likely to want to become homeowners and therefore to receive support achieving that. Likewise, those who married may have received financial support organizing their wedding and are also more likely to aspire to home-ownership. No effects were found of whether the respondent had children or had ever divorced.

The relationship between the parents at the respondent's age 15 is not significantly associated with monetary support from parents, nor with ownership support. In line with the idea that parental divorce is associated with a lower quality of parent-child relationships, particularly when the divorce took place when the child was young, we see a negative effect of parental divorce before the respondent turned 18 on the likelihood of 
financial support and (albeit only marginally significant) on home-ownership support. For parental divorce after the respondent turned 18, we see no effect on money transfers. For home-ownership support the effect parameter of parental divorce before the respondent reached the age of 18 is similar to the parameter for monetary support, although it is not significant. The effect of parental divorce after the respondent had turned 18 years old on receiving ownership support is negative, but not significant. The difference between women and men in receiving monetary support is insignificant and estimated to be very small. The gender difference in receiving home-ownership support is also insignificant, but seems to be more in line with a greater inclination of men to want help with homeownership than with the reinforcement of better parent-daughter than parent-son relationships. No significant impact on monetary support was found of the distance between the respondent's current place of residence and the place of residence at age 15, but the association with home-ownership support was negative and significant: the greater the distance, the smaller the likelihood of home-ownership support.

\subsection{Differences between money support and home-ownership support}

Parental home-ownership was found to have a great impact on both monetary support and home-ownership support. No significant differences between the parameter estimates were found. In other words, there was no indication that homeowner parents are particularly keen on assisting their adult children in becoming homeowners rather than just giving them money. They seem to be just more likely to support their children financially, for whatever purpose, than renters.

Some other noteworthy differences between the models were found. Most of these point to greater effects in the model of home-ownership support than in the model of monetary help. This is true of the effect of higher vocational or university education of the father, number of siblings, death of the father before the respondent turned 18 years old, and higher vocational education of the adult child. Possibly, because home-ownership support tends to require larger amounts than other monetary support, the dependence on parental resources is greater for home-ownership support. A difference in the effects of a missing socio-economic status of the respondent's job is noticeable but hard to interpret: this effect is negative for monetary support but insignificant (and slightly positive) for home-ownership support. A difference in the impact of distance to the place of residence in the respondent's youth is also noticeable: a negative impact was only found for home-ownership support. This specificity to home-ownership support is in line with the idea that parents use homeownership support to keep their children close (and thus with reversed causality), but may also be caused by a lower geographical mobility of home-owning adult children.

\subsection{Control variables}

As expected, the respondent's age was positively associated with the likelihood of homeownership support, but hardly any age effect was found for other monetary support. No significant effects were found of being foreign-born.

\section{Conclusions}

In this paper we investigated the impact of parental resources, and various characteristics of parents and adult children that were supposed to indicate the parents' willingness to 
support their children, on home-ownership support and other substantial financial transfers. Compared with previous work on parent-child transfers, a new feature of the research for this paper was the use of these two types of support and a formal test of whether the effects of the independent variables differed between the types. It was hypothesized that parental home-ownership would be more important to home-ownership support than to other financial support. If this were the case, this would lend support to the idea that homeowner parents use their resources specifically to promote their children's home-ownership.

As expected and in line with previous research, parental home-ownership appeared to be crucial to the likelihood that parents provide financial support to their children. But no evidence whatsoever was found in favor of the ownership promotion hypothesis: that this would particularly be the case for home-ownership support. Apparently, homeowner parents do not tend to favor home-ownership support over other financial support.

This is certainly not to say such deliberate ownership promotion does not play a part in the intergenerational transmission of home-ownership. Very likely, there are other ways in which homeowner parents encourage their children to become homeowners. Parents may use loans and mortgage guarantees to support their children in entering owner-occupied housing. Measures for these types of support were, unfortunately, not available in our data. Parents may also socialize their children towards home-ownership, either by giving an example that the children want to follow or by telling them home-ownership is the right choice (Henretta 1984; Smits and Mulder 2008).

Of the statistically significant differences in impacts of the independent variables between the model of home-ownership support and the model of other financial support, most seemed to indicate a greater importance of resources to home-ownership support than to other financial support. This makes it all the more remarkable that such a difference was not found for parental home-ownership. Another difference was found for the association between the likelihood of support and the distance to the place of residence when the respondent was 15 years old: the likelihood of home-ownership support decreased with distance, but this was not the case for other financial support. A decrease of support with distance was hypothesized from the point of view that the greater frequency of contact among those who live close may be reflected in a better relationship quality and a greater willingness of the parents to provide financial support. It is difficult to see why this argument would hold for home-ownership support but not for other financial support. The proposed mechanism might still play a role, but Tomassini et al. (2003) might also be right in arguing that parents use home-ownership support to help their children buy a home close to theirs. Alternatively, this finding may be due to the smaller inclination of homeowners to move long distances (Helderman et al. 2006).

The results of the analyses provide additional support for the already well-established finding that parents with more resources are more likely to provide financial support to their children. In contrast, no support was found for another well-known hypothesis: that it is particularly the needy children-those with low incomes-who receive financial assistance. The previous evidence related to this hypothesis was mixed. Apparently, the direction of the association between the likelihood of financial parent-child support and the child's income is sensitive to such factors as the measurement of support, the population under study or the context in which the support is studied. For example, parents might tend to respond to their children's short-term financial problems, but not to longer-term lower earnings as indicated by the socio-economic status measure used in this study. A more thorough investigation of the circumstances under which parents respond to their children's financial needs could be undertaken in future research. 
Adult children's characteristics that enhance their likelihood of receiving support seem to be high education and marriage. Both these findings are in line with the idea that parents support their children as a reward for merit. But the story might be simpler than that. Married and highly educated people are more likely to become homeowners (Mulder and Wagner 1998) and this simple fact may make them also more likely to receive homeownership support. Other financial support may be more likely for the married because some of them were supported for their wedding, and for the highly educated because they received help for paying their cost of living and tuition fees while studying. If this is the case, the motivation for the support may still be merit: parents may be happy to support their children's marriage or enrolment in education, possibly more so than supporting the purchase of consumption goods. But the support may also be motivated by having a concrete occasion to help.

The idea that parents provide financial assistance to their children to reinforce a good relationship got some support: those with divorced parents-particularly if the divorce took place before the respondent turned 18-were less likely than others to have received financial support. It should be noted, however, that this result could also be interpreted from a resource perspective: divorced parents are likely to have fewer resources than married parents. The results for the parental relationship quality when the respondent was 15 years old, however, did not support the reinforcement perspective.

The study was carried out in the Netherlands, a country in which rather individualistic values prevail with, thus far, a rather generous welfare system, a moderate proportion of homeowners, and a well-developed mortgage market in which many adult children achieve home-ownership without parental help. It is unclear to what extent and how this context has affected the results. Future research could address differences between contexts in the likelihood of parent-child housing support and other financial support.

The main limitation of this study is the limited opportunity the data offer to distinguish causes from effects. This is less true of the parental resources-most were measured at age 15 of the respondent-but more so of the indicators of the parents' willingness to support the adult child. Because the timing of the financial support is unknown, it is also unknown whether the support was given before or after, for example, a marriage or a divorce. The use of longitudinal data could solve this problem.

Despite this limitation, the data offered a nice opportunity to enhance the scientific knowledge on financial parent-child transfers and to test a hypothesis derived from the idea that homeowner parents use their resources specifically to encourage their children's homeownership.

Acknowledgments Both authors did part of their work for this article when they were employed by the Amsterdam Institute for Social Science Research of the University of Amsterdam, Department of Geography, Planning and International Development Studies (Mulder) and Department of Sociology (Smits).

Open Access This article is distributed under the terms of the Creative Commons Attribution License which permits any use, distribution, and reproduction in any medium, provided the original author(s) and the source are credited.

\section{References}

Albertini, M., Kohli, M., \& Vogel, C. (2007). Intergenerational transfers of time and money in European families: Common patterns different regimes? Journal of European Social Policy, 17(4), 319-334. 
Altonji, J. G., Hayashi, F., \& Kotlikoff, L. J. (1997). Parental altruism and inter vivos transfers: Theory and evidence. Journal of Political Economy, 105(6), 1121-1166.

Amato, P. R., Rezac, S. J., \& Booth, A. (1995). Helping between parents and young adult offspring: The role of parental marital quality, divorce, and remarriage. Journal of Marriage and the Family, 57(2), 363-374.

Attias-Donfut, C., Ogg, J., \& Wolff, F.-C. (2005). European patterns of intergenerational financial and time transfers. European Journal of Ageing, 2(3), 161-173.

Attias-Donfut, C., \& Wolf, F.-C. (2000). Complementarity between private and public transfers. In S. Arber \& C. Attias-Donfut (Eds.), The myth of generational conflict. The family and state in ageing societies (pp. 47-68). London/New York: Routledge.

Berry, B. (2008). Financial transfers from living parents to adult children: Who is helped and why? American Journal of Economics and Sociology, 67(2), 207-239.

Blaauboer, M. (2010). Family background, individual resources and the homeownership of couples and singles. Housing Studies, 25(4), 441-461.

Blaauboer, M., \& Mulder, C. H. (2010). Gender differences in the impact of family background on leaving the parental home. Journal of Housing and the Built Environment, 25, 53-71.

Bonvalet, C., \& Maison, D. (2007). The family circle: Spatial proximity and personal affinity. In C. Bonvalet, A. Gotman, \& Y. Grafmeyer (Eds.), Family kinship and place in France (Z. Andreyev Trans.). (Vol. 2, pp. 27-68). London: Southern Universities Press.

Clogg, C. C., Petkova, E., \& Haritou, A. (1995). Statistical methods for comparing regression coefficients between models. American Journal of Sociology, 100, 1261-1293.

Cooney, T. M., \& Uhlenberg, P. (1990). The role of divorce in men's relations with their adult children after mid-life. Journal of Marriage and the Family, 52(3), 677-688.

Cox, D. (1987). Motives for private income transfers. Journal of Political Economy, 95(3), 508.

Cox, D., \& Rank, M. R. (1992). Inter-vivos transfers and intergenerational exchange. The review of economics and statistics, 74(2), 305-314.

De Jong Gierveld, J., \& Dykstra, P. A. (2002). The long-term rewards of parenting: Older adults' marital history and the likelihood of receiving support from adult children. Ageing International, 27(3), 49-69.

Dykstra, P. A., Kalmijn, M., Knijn, T. C. M., Komter, A. E., Liefbroer, A. C., \& Mulder, C. H. (2005). Codebook of the Netherlands Kinship Panel Study, a multi-actor, multi-method panel study on solidarity in family relationships, Wave 1. The Hague: Netherlands Interdisciplinary Demographic Institute (NKPS Working Paper No. 4).

Dykstra, P. A., Kalmijn, M., Knijn, T. C. M., Komter, A. E., Liefbroer, A. C., \& Mulder, C. H. (2007). Codebook of the Netherlands Kinship Panel Study, a multi-actor, multimethod panel study on solidarity in family relationships, Wave 2. The Hague: Netherlands Interdisciplinary Demographic Institute (NKPS Working Paper No. 6).

Eggebeen, D. J., \& Hogan, D. P. (1990). Giving between generations in American families. Human Nature, 1(3), 211-232.

Engelhardt, G. V., \& Mayer, C. J. (1994). Gifts for home purchase and housing market behaviour. New England Economic Review pp 47-58.

Engelhardt, G. V., \& Mayer, C. J. (1998). Intergenerational transfers, borrowing constraints, and saving behaviour: Evidence from the housing market. Journal of Urban Economics, 44(1), 135-157.

Furstenberg, F. F. J., Hoffman, S. D., \& Shrestha, L. (1995). The effect of divorce on intergenerational transfers: New evidence. Demography, 32(3), 319-333.

Ganzeboom, H. B. G., De Graaf, P., \& Treiman, D. J. (1992). A standard international socio-economic index of occupational status. Social Science Research, 21, 1-56.

Greenwell, L., \& Bengtson, V. L. (1997). Geographic distance and contact between middle-aged children and their parents: The effects of social class over 20 years. The Journals of Gerontology: Series B, $52 B(1)$, S13-S26.

Grundy, E. (2005). Reciprocity in relationships: Socio-economic and health influences on intergenerational exchanges between Third Age parens and their adult children in Great Britain. British Journal of Sociology, 56(2), 233-255.

Guiso, L., \& Jappelli, T. (2002). Private transfers, borrowing constraints, and the timing of homeownership. Journal of Money, Credit and Banking, 34(2), 315-339.

Gulbrandsen, L., \& Langsether, A. (2003). Family transactions in the Norwegian housing market. Housing, Theory and Society, 20(3), 137-152.

Helderman, A. C., \& Mulder, C. H. (2007). Intergenerational transmission of homeownership: The roles of gifts and continuities in housing market characteristics. Urban Studies, 44(2), 231-247.

Helderman, A. C., Van Ham, M., \& Mulder, C. H. (2006). Migration and home ownership. Tijdschrift voor Economische en Sociale Geografie, 97(2), 111-125. 
Henretta, J. C. (1984). Parental status and child's home ownership. American Sociological Review, 49, $131-140$.

Henretta, J. C. (1987). Family transitions, housing market context, and first home purchase by young married households. Social Forces, 66(2), 520-536.

Henretta, J. C., Grundy, E., \& Harris, S. (2002). The influence of socio-economic and health differences on parents' provision of help to adult children: A British-United States comparison. Ageing and Society, 22(4), 441-458.

Kohli, M. (1999). Private and public transfers between generations: Linking the family and the state. European Societies, 1(1), 81-104.

Litwak, E., \& Kulis, S. (1987). Technology, proximity, and measures of kin support. Journal of Marriage and the Family, 49(3), 649-661.

Mayer, C. J., \& Engelhardt, G. V. (1996). Gifts, down payments, and housing affordability. Journal of Housing Research, 7(1), 59-77.

McGarry, K., \& Schoeni, R. F. (1997). Transfer behavior within the family: Results from the asset and health dynamics study. The Journals of Gerontology: Series B, 52B(Special Issue), 82-92.

Motel-Klingebiel, A., Tesch-Römer, C., \& Von Kondratowitz, H.-J. (2005). Welfare states do not crowd out the family: Evidence for mixed responsibility from comparative analyses. Ageing \& Society, 25(06), 863-882.

Mulder, C. H. (2007). The family context and residential choice: A challenge for new research. Population, Space and Place, 13, 265-278.

Mulder, C. H., \& Billari, F. C. (2010). Home-ownership regimes and low fertility. Housing Studies, 25(4), 527-541.

Mulder, C. H., \& Smits, J. (1999). First-time home-ownership of couples: The effect of inter-generational transmission. European Sociological Review, 15(3), 323-337.

Mulder, C. H., \& Van der Meer, M. J. (2009). Geographical distances and support from family members. Population, Space and Place, 15(4), 381-399.

Mulder, C. H., \& Wagner, M. (1998). First-time home-ownership in the family life course: A West GermanDutch comparison. Urban Studies, 35(4), 687-713.

Pezzin, L. E., \& Schone, B. S. (1999). Parental marital disruption and intergenerational transfers: An analysis of lone elderly parents and their children. Demography, 36(3), 287-297.

Poggio, T. (2008). The intergenerational transmission of home ownership and the reproduction of the familialistic welfare regime. In C. Saraceno (Ed.), Families, ageing and social policy (pp. 59-87). Cheltenham: Edward Elgar.

Reil-Held, A. (2006). Crowding out or crowding in? Public and private transfers in Germany. European Journal of Population, 22(3), 263-280.

Rossi, A. S., \& Rossi, P. H. (1990). Of human bonding: Parent-child relations across the life course. New York: Aldine de Gruyter.

Smits, A., \& Mulder, C. H. (2008). Family dynamics and first-time homeownership. Housing Studies, 23(6), 917-933.

Tomassini, C., Wolf, D. A., \& Rosina, A. (2003). Parental housing assistance and parent-child proximity in Italy. Journal of Marriage and the Family, 65, 700-715. 